\title{
Preterm Birth: A Prominent Risk Factor for Low Apgar Scores
}

\author{
Maria Svenvik, ${ }^{1}$ Lars Brudin, ${ }^{2,3}$ and Marie Blomberg ${ }^{4}$ \\ ${ }^{1}$ Department of Obstetrics and Gynecology, Kalmar County Hospital, 39185 Kalmar, Sweden \\ ${ }^{2}$ Department of Clinical Physiology, Kalmar County Hospital, 39185 Kalmar, Sweden \\ ${ }^{3}$ Department of Medicine and Health Sciences, Linköping University Hospital, 58185 Linköping, Sweden \\ ${ }^{4}$ Department of Obstetrics and Gynecology, and Department of Clinical and Experimental Medicine, Linköping University, \\ 58183 Linköping, Sweden \\ Correspondence should be addressed to Marie Blomberg; marie.blomberg@lio.se
}

Received 2 January 2015; Accepted 5 February 2015

Academic Editor: Igor Hudic

Copyright (C) 2015 Maria Svenvik et al. This is an open access article distributed under the Creative Commons Attribution License, which permits unrestricted use, distribution, and reproduction in any medium, provided the original work is properly cited.

Objective. To determine predictive risk factors for Apgar scores $<7$ at 5 minutes at two hospitals providing tertiary care and secondary care, respectively. Methods. A retrospective registry cohort study of 21126 births (2006-2010) using data from digital medical records. Risk factors were analyzed by logistic regression analyses. Results. $\mathrm{AS}^{5 \mathrm{~min}}<7$ was multivariately associated with the following: preterm birth; gestational week $32+0-36+6$, OR = $3.9(95 \%$ CI 2.9-5.3); week $28+0-31+6$, OR = 8 (5-12); week $<28+0$, OR = 15 (8-29); postterm birth, OR = 2.0 (1.7-2.3); multiple pregnancy, OR = 3.53 (1.79-6.96); previous cesarean section, $\mathrm{OR}=3.67$ (2.31-5.81); BMI 25-29, OR = $1.30(1.09-1.55) ; \mathrm{BMI} \geq 30$ OR = $1.70(1.20-2.41)$; nonnormal CTG at admission, $\mathrm{OR}=1.98(1.48-2.66) . \geq 1$-para was associated with a decreased risk for $\mathrm{AS}^{5 \mathrm{~min}}<7, \mathrm{OR}=0.34(0.25-0.47)$. In the univariate logistic regression analysis $\mathrm{AS}^{5 \mathrm{~min}}<7$ was associated with tertiary level care, OR $=1.48(1.17-1.87)$; however, in the multivariate analysis there was no significant difference. Conclusion. A number of partially preventable risk factors were identified, preterm birth being the most evident. Further, no significant difference between the two hospital levels regarding the risk for low Apgar scores was detected.

\section{Introduction}

The Apgar score, regardless of underlying cause, is used for comparing the neonatal outcome at different obstetrical units worldwide in order to measure the quality of obstetrical care. The Apgar score still defines the degree of birth asphyxia according to the International Statistical Classification of Diseases and Related Health Problems 10th Revision (ICD-10) [1], despite other available methods indicating birth asphyxia such as umbilical cord acid base balance measurement.

A low Apgar score less than seven points at five minutes is known to have implications for neonatal mortality [2] and morbidity, for example, respiratory distress and neurological problems $[3,4]$. Still, the vast majority of infants with Apgar $<7$ points at five minutes $\left(\mathrm{AS}^{5 \mathrm{~min}}<7\right)$ will be healthy both during the neonatal period and later on in life.

Previous national and international studies have demonstrated a number of risk factors for low Apgar scores or asphyxia, although results and definitions differ. The studies comprise socioeconomic, demographic, and medical risk factors. Smoking [5], low socioeconomic status [6], single civil status of the mother [7], maternal short stature $[8,9]$, and maternal obesity $[10,11]$ have all been shown to increase the risk for a low Apgar score. The mode of delivery, intrauterine meconium release, and abnormalities in cardiotocography (CTG) [7] comprise medical risk factors associated with a low Apgar score. There are no available comprehensive studies evaluating the state of modern Swedish obstetric health care.

The aims of the study were to investigate whether there are identifiable risk factors of $\mathrm{AS}^{5 \mathrm{~min}}<7$ prior to delivery and to compare possible differences in risk factor profiles between the level of care at a university hospital providing tertiary care and a county hospital providing secondary care.

\section{Materials and Methods}

This retrospective register study is a comprehensive study of all 21126 deliveries during five consecutive years (2006-2010) 
at a secondary level hospital (the County Hospital in Kalmar) and a tertiary level hospital (the University Hospital in Linköping), both situated in the southeastern region of Sweden. Parturients and infants were identified from the local digital medical records, Obstetrix (Siemens Healthcare, Health Services, Upplands Väsby, Sweden), which include standardized medical record forms completed at the antenatal health care centers at the start of prenatal care (usually in gestational week 10-12), records from the delivery units, and records from the pediatric examination of the newborn. Ninety percent visit the antenatal health care center during the first trimester of pregnancy (local data). The system is identical at both hospitals.

The study population was divided into infants with an $\mathrm{AS}^{5 \mathrm{~min}}<7$ and infants with an Apgar score $\geq 7$ at five minutes $\left(A S^{5 \text { min }} \geq 7\right)$. Infants, who had not been given an Apgar score at five minutes were excluded $(n=136)$. Stillbirths due to intrauterine fetal death (IUFD) were also excluded $(n=72)$, as were infants with lethal malformations $(n=3$; anencephaly, Potter syndrome and trisomy 18).

In cases of multiple pregnancies $(n=619)$ one of twins or two of triplets $(n=6)$ were excluded in order to avoid recording potential maternal risk factors more than once in the same pregnancy. Among siblings where one had an $\mathrm{AS}^{5 \mathrm{~min}}<7$ while the other had an $\mathrm{AS}^{5 \mathrm{~min}} \geq 7$, those with $\mathrm{AS}^{5 \mathrm{~min}}<7$ were included in the study. When both infants in a pair of twins had an $\mathrm{AS}^{5 \mathrm{~min}}<7$ or both had an $\mathrm{AS}^{5 \mathrm{~min}} \geq 7$, one was randomly excluded.

Due to partial overlapping (e.g., twin and IUFD) in the mentioned exclusion criteria 483 infants were excluded. A total of $20643(97.7 \%)$ patients were available for further analysis.

From the medical records data was extracted regarding maternal age, height, and weight, single or multiple pregnancy, parity, smoking habits during pregnancy, previous cesarean section, previous or current illnesses in certain categories (type 1 diabetes mellitus, endocrine diseases (i.e., not diabetes mellitus, predominantly thyroid disease), epilepsy and inflammatory bowel disease (IBD)), induction versus spontaneous onset of labor, classification of the CTG at admission, gestational age at delivery, mode of delivery, time of delivery, and diagnoses at delivery including preeclampsia if existent.

Body mass index (BMI) in $\mathrm{kg} / \mathrm{m}^{2}$ was calculated from maternal prepregnancy weight and height data. Women were grouped into six categories of BMI: underweight (less than 18.5), normal weight (18.5-24.9), overweight (25-29.9), obesity class I (30-34.9), obesity class II (35-39.9), and obesity class III (40 or more) according to the World Health Organization classification [12]. All these maternal and delivery variables were considered potential risk factors for low Apgar scores and were compared between infants with $\mathrm{AS}^{5 \text { min }}<7$ and infants with $\mathrm{AS}^{5 \mathrm{~min}} \geq 7$. Secondly, these variables were compared concerning infants with $\mathrm{AS}^{5 \mathrm{~min}}<7$ and infants with $\mathrm{AS}^{5 \mathrm{~min}} \geq 7$ between the two hospital levels included in the study.

Continuous variables with symmetric distribution (e.g., age and weight) are presented as the mean value (mean), standard deviation (SD) and range ( $\min -\max$ ), and categorized for logistic regression analysis. The difference between groups with respect to these variables was analyzed with Student's $t$-test adjusted for unequal variances. Risk factors for $\mathrm{AS}^{5 \mathrm{~min}}<7$ were analyzed by logistic regression analysis. Significant associations of $\mathrm{AS}^{5 \mathrm{~min}}<7$ in the univariate analysis and age were included in the subsequent multivariate logistic regression analysis. In this analysis, data is presented as odds ratios (OR) with $95 \%$ confidence intervals (CI). All $P$ values are two-tailed and $P=0.05$ is considered statistically significant. The software Statistica v.12 (StatSoft, Inc., Tulsa, OK, USA) was used for all analyses.

The study was approved by the Regional Ethical Review Board in Linköping, Sweden (2012/195-31).

\section{Results}

Of 21126 infants 20990 (99.4\%) had been assigned an Apgar score at five minutes of age. After described exclusions a total number of 20643 were considered the study population. From the tertiary level hospital 13632 infants were included, of which 273 had $\mathrm{AS}^{5 \mathrm{~min}}<7$ (2.00\%). From the secondary level hospital, the corresponding figures were 96/7011 (1.37\%).

There was no difference in maternal age or maternal weight between the group with an $\mathrm{AS}^{5 \mathrm{~min}}<7$ and an $\mathrm{AS}^{5 \mathrm{~min}} \geq 7$ (Table 1), but maternal height was significantly shorter in the group with $\mathrm{AS}^{5 \mathrm{~min}}<7$. The BMI was significantly higher in the group with $\mathrm{AS}^{5 \mathrm{~min}}<7$ and there was a clear trend over the BMI strata as well as for gestational age (Table 2). The mean gestational age was significantly shorter in $\mathrm{AS}^{5 \mathrm{~min}}<7$ (Table 1$)$.

$\mathrm{AS}^{5 \mathrm{~min}}<7$ was multivariately associated with the following parameters (Table 3): preterm birth, postterm birth, multiple pregnancy, previous cesarean section, preeclampsia, maternal height $\leq 158 \mathrm{~cm}, \mathrm{BMI} 25-29$, and BMI $\geq 30$. Being $\geq$ 1-para was associated with a decreased risk for $\mathrm{AS}^{5 \mathrm{~min}}<$ 7. In the univariate logistic regression analysis $\mathrm{AS}^{5 \mathrm{~min}}<$ 7 was associated with tertiary level care. However, in the multivariate analysis no significant difference was found. This was also the case for thyroid disease. Neither type 1 diabetes mellitus, IBD, nor epilepsy was significant risk factors for $\mathrm{AS}^{5 \mathrm{~min}}<7$.

Analyses were also performed to investigate whether or not the time of birth (day/night or seasonal) was a risk factor for a low Apgar score, but no significant difference was found.

Furthermore, different types of delivery modes were investigated for the frequency of low Apgar scores. There was no significant difference between spontaneous vaginal birth $\left(0.91 \% \mathrm{AS}^{5 \mathrm{~min}}<7\right)$ and elective cesarean section $(1.24 \%)$ or between operative vaginal delivery $(4.68 \%)$ and emergency cesarean section (5.70\%). In the group delivered by immediate emergency cesarean section, however, there was a significantly higher frequency of $\mathrm{AS}^{5 \mathrm{~min}}<7(20.9 \%$, $P<0.001)$.

Moreover, a subanalysis was performed in order to investigate risk factors in the study population for birth before 32 weeks of gestation (Table 4 ), which was multivariately associated with multiple pregnancy, preeclampsia, smoking, 
TABLE 1: Descriptive data for the study population $(n=20643)$. Differences between $\mathrm{AS}^{5 \mathrm{~min}}<7$ and $\mathrm{AS}^{5 \text { min }} \geq 7$ were analyzed with Student's $t$-test.

\begin{tabular}{|c|c|c|c|c|c|c|c|}
\hline & \multicolumn{3}{|c|}{$\mathrm{AS}^{5 \mathrm{~min}}<7$} & \multicolumn{3}{|c|}{$\mathrm{AS}^{5 \mathrm{~min}} \geq 7$} & \multirow{2}{*}{$P$} \\
\hline & $n$ & Mean (SD) & Q1-Q3 & $n$ & Mean (SD) & Q1-Q3 & \\
\hline Age (years) & 369 & $30(5)$ & $26-34$ & 20274 & $30(5)$ & $26-33$ & 0.891 \\
\hline Weight (kg) & 303 & $70(15)$ & $59-78$ & 18314 & $69(14)$ & $59-75$ & 0.133 \\
\hline Height $(\mathrm{cm})$ & 306 & $164(7)$ & $160-168$ & 18570 & $166(6)$ & $162-170$ & $<0.001$ \\
\hline Body mass index $\left(\mathrm{kg} / \mathrm{m}^{2}\right)$ & 301 & $26(5)$ & $22-29$ & 18239 & $25(5)$ & $22-27$ & $<0.001$ \\
\hline Gestational age (weeks) & 366 & $36(6)$ & $32-41$ & 20251 & $40(2)$ & $39-41$ & $<0.001$ \\
\hline
\end{tabular}

TABle 2: Categorized descriptive data for the study population regarding body mass index (BMI) and gestational age. Chi2-test was used for the comparison of frequencies.

\begin{tabular}{lccccc}
\hline \multirow{2}{*}{ Parameter } & $\mathrm{AS}^{5 \mathrm{~min}}<7$ & $\mathrm{AS}^{5 \mathrm{~min}} \geq 7$ & \multirow{2}{*}{$\begin{array}{c} \\
\end{array}$} \\
& $n$ & $(\%)$ & $n$ & $(\%)$ & \\
\hline BMI $\left(\mathrm{kg} / \mathrm{m}^{2}\right)$ & 21 & 7.0 & 1746 & 9.6 & \\
$\quad<20$ & 135 & 44.9 & 9457 & 51.9 & \\
$20-24.9$ & 84 & 27.9 & 4778 & 26.2 & \\
$25-29.9$ & 46 & 15.3 & 1566 & 8.6 & \\
$30-34.9$ & 15 & 5.0 & 692 & 3.8 & $<0.001^{*}$ \\
$\geq 35$ & $\mathbf{3 0 1}$ & $\mathbf{1 0 0}$ & $\mathbf{1 8 2 3 9}$ & $\mathbf{1 0 0}$ & \\
Total & & & & & \\
Gestational age (weeks) & 62 & 16.9 & 49 & 0.2 & \\
$<28$ & 27 & 7.4 & 122 & 0.6 & \\
$28-31+6$ & 45 & 12.3 & 981 & 4.8 & \\
$32-36+6$ & 206 & 56.3 & 18045 & 89.1 & \\
$37-41+6$ & 26 & 7.1 & 1054 & 5.2 & $<0.001$ \\
$\geq 42$ & $\mathbf{3 6 6}$ & $\mathbf{1 0 0}$ & $\mathbf{2 0 2 5 1}$ & $\mathbf{1 0 0}$ & \\
Total & & & & & \\
\hline
\end{tabular}

${ }^{*}$ Sign difference between $\mathrm{BMI} \geq 30$ and $\mathrm{BMI}<30(P<0.001)$.

thyroid disease, and epilepsy. Being $\geq 1$-para was associated with a decreased risk for birth before 32 weeks of gestation.

\section{Discussion}

This retrospective registry study showed that maternal height $<158 \mathrm{~cm}, \mathrm{BMI}>30 \mathrm{~kg} / \mathrm{m}^{2}$, nulliparity, postterm birth $(\geq 42$ weeks of gestation), preterm birth $(\leq 36+6$ weeks of gestation), previous cesarean section, multiple pregnancy, preeclampsia, and an abnormal CTG at admission were independent risk factors for $\mathrm{AS}^{5 \mathrm{~min}}<7$.

The study has some limitations. One is that the cases of $\mathrm{AS}^{5} \mathrm{~min}<7$ are relatively few, as they constitute $1.98 \%$ of the total study population. This could be rectified by a larger study population. As the number of children with an $\mathrm{AS}^{5 \mathrm{~min}} \geq 7$, however, is relatively large, the risk factor analysis should be considered fairly robust.

A low Apgar score does not always correlate to neonatal asphyxia on the basis of metabolic acidosis. The analysis of umbilical cord $\mathrm{pH}$ and base excess was not included in this study, which could have been valuable in order to further elucidate the entity of infants with low Apgar scores.
However, it has been previously shown that only about $38 \%$ of children with low Apgar scores have metabolic acidosis [13]. In another study $69 \%$ of children with an Apgar score of 1-3 at 5 minutes and $54 \%$ of children with an Apgar score of 4-6 at 5 minutes had a $\mathrm{pH}$ of $<7.15$ in the umbilical artery [14]. On the other hand, not all neonates with metabolic acidosis have low Apgar scores [14, 15]. Although the pathophysiology of low Apgar scores differ, a low score identifies children in need of resuscitation efforts at birth. An advantage of using the Apgar score as a selection criterion, and not metabolic acidosis, is that the vast majority of infants were given an Apgar score (in this material $20990 / 21126=99.4 \%$ ) whereas complete registration of umbilical cord blood gases were at hand for only about $70-75 \%$, thereby missing about $25-30 \%$ (local data).

In this study we chose to include all live births during the relevant time period at two hospitals. We did not set a minimum threshold for inclusion regarding gestational age, which was often the case in other studies aiming to investigate risk factors for low Apgar scores, neonatal asphyxia, or hypoxic ischemic encephalopathy $[7,10,16]$. We also chose not to exclude cases of multiple gestation, as the purpose was to comprehensively investigate risk factors for $\mathrm{AS}^{5 \mathrm{~min}}<$ 7. In similar studies exclusively singleton pregnancies were included [7, 16]. Our study, therefore, presents a more genuine view of the risk factors for low Apgar scores among patients at a standard Swedish obstetric unit.

This study focused on maternal risk factors and only those easily accessible in the digital medical journals. One advantage of using medical journals as a data source is that this enables including variables not available in the Swedish Medical Birth register. Here, for example, we have the possibility to evaluate the CTG at admission. This is a strength of the study.

Regarding fetal risk factors, we have studied the impact of gestational age and normal or abnormal CTG at admission. In this kind of study it is not possible, however, to further evaluate CTG or the use of an ST-analysis. It would be of value to investigate other potential fetal risk factors, such as intrauterine growth restriction or oligohydramniosis. However, we estimated the material as too small for this purpose. Another problem with those factors is that they may not have been diagnosed prior to delivery.

Although height and BMI are so closely linked, maternal short stature $(\leq 158 \mathrm{~cm})$ and BMI $>30 \mathrm{~kg} / \mathrm{m}^{2}$ were both found to be independent risk factors for $\mathrm{AS}^{5 \mathrm{~min}}<7$, even when adjusted for in the multivariate regression analysis. However, 
TABLE 3: Risk factors for Apgar scores $<7$ at 5 minutes. Analyses performed by univariate and multivariate logistic regression.

\begin{tabular}{|c|c|c|c|c|c|c|c|c|c|}
\hline & \multirow{2}{*}{ Total } & \multicolumn{2}{|c|}{$\mathrm{AS}^{5 \mathrm{~min}}<7$} & \multicolumn{3}{|c|}{ Univariate logistic regression } & \multicolumn{3}{|c|}{ Multivariate logistic regression } \\
\hline & & $n$ & $(\%)$ & OR & $95 \%$ conf. int. & $P$ & OR & $95 \%$ conf. int. & $P$ \\
\hline \multicolumn{10}{|l|}{ Level of care } \\
\hline Secondary & 7011 & 96 & 1.37 & 1.00 & & & & & \\
\hline Tertiary & 13632 & 273 & 2.00 & 1.48 & $1.17-1.87$ & 0.001 & - & - & - \\
\hline \multicolumn{10}{|l|}{ Age (years) } \\
\hline$\leq 26$ & 5387 & 100 & 1.86 & 1.00 & & & 1.00 & & \\
\hline $27-30$ & 5976 & 102 & 1.71 & 1.01 & $0.92-1.10$ & & 1.10 & $0.97-1.24$ & \\
\hline $31-33$ & 4343 & 72 & 1.66 & 1.01 & $0.84-1.22$ & & 1.20 & $0.93-1.54$ & \\
\hline$\geq 34$ & 4937 & 95 & 1.92 & 1.02 & $0.77-1.34$ & 0.897 & 1.31 & $0.90-1.91$ & 0.152 \\
\hline \multicolumn{10}{|l|}{ Height (cms) } \\
\hline$\geq 175$ & 1800 & 17 & 0.94 & 1.00 & & & 1.00 & & \\
\hline $159-174$ & 14992 & 229 & 1.53 & 1.83 & $1.44-2.32$ & & 2.06 & $1.56-2.72$ & \\
\hline$\leq 158$ & 2084 & 60 & 2.88 & 3.34 & $2.06-5.39$ & $<0.001$ & 4.23 & $2.43-7.39$ & $<0.001$ \\
\hline \multicolumn{10}{|l|}{ BMI $\left(\mathrm{kg} / \mathrm{m}^{2}\right)$} \\
\hline$<25$ & 11359 & 156 & 1.37 & 1.00 & & & 1.00 & & \\
\hline $25-29.9$ & 4862 & 84 & 1.73 & 1.38 & $1.19-1.60$ & & 1.29 & $1.08-1.54$ & \\
\hline$\geq 30$ & 2319 & 61 & 2.63 & 1.91 & $1.43-2.56$ & $<0.001$ & 1.67 & $1.17-2.36$ & 0.004 \\
\hline \multicolumn{10}{|l|}{ Smoking } \\
\hline No & 15784 & 246 & 1.56 & 1.00 & & & & & \\
\hline Yes & 3236 & 62 & 1.92 & 1.25 & $0.95-1.66$ & 0.113 & - & - & - \\
\hline \multicolumn{10}{|l|}{ Thyroid disease } \\
\hline No & 18379 & 290 & 1.58 & 1.00 & & & & & \\
\hline Yes & 550 & 17 & 3.09 & 1.99 & $1.21-3.27$ & 0.007 & - & - & - \\
\hline \multicolumn{10}{|c|}{ Type 1 diabetes mellitus } \\
\hline No & 18823 & 302 & 1.60 & 1.00 & & & & & \\
\hline Yes & 134 & 5 & 3.73 & 1.21 & $0.97-5.85$ & 0.059 & - & - & - \\
\hline \multicolumn{10}{|c|}{ Inflammatory bowel disease } \\
\hline No & 18762 & 302 & 1.61 & 1.00 & & & & & \\
\hline Yes & 194 & 5 & 2.58 & 1.62 & $0.66-3.96$ & 0.292 & - & - & - \\
\hline \multicolumn{10}{|l|}{ Epilepsy } \\
\hline No & 18798 & 303 & 1.61 & 1.00 & & & & & \\
\hline Yes & 158 & 4 & 2.53 & 1.59 & $0.58-4.30$ & 0.366 & - & - & - \\
\hline \multicolumn{10}{|l|}{ Parity } \\
\hline 0 & 8418 & 191 & 2.27 & 1.00 & & & 1.00 & & \\
\hline$\geq 1$ & 10602 & 117 & 1.10 & 0.48 & $0.38-0.60$ & $<0.001$ & 0.34 & $0.25-0.48$ & $<0.001$ \\
\hline \multicolumn{10}{|c|}{ Gestational age (weeks) } \\
\hline $37+0-41+6$ & 18251 & 206 & 1.13 & 1.00 & & & 1.00 & & \\
\hline$\geq 42+0$ & 1080 & 26 & 2.41 & 2.8 & $2.6-3.1$ & & 2.0 & $1.7-2.3$ & \\
\hline $32+0-36+6$ & 1026 & 45 & 4.39 & 8.0 & $6.8-9.4$ & & 3.9 & $2.9-5.3$ & \\
\hline $28+0-31+6$ & 149 & 27 & 18.1 & 23 & $18-29$ & & 8 & $5-12$ & \\
\hline$<28+0$ & 111 & 62 & 55.9 & 64 & $46-88$ & $<0.001$ & 15 & $8-29$ & $<0.001$ \\
\hline \multicolumn{10}{|c|}{ Previous cesarean section } \\
\hline No & 17796 & 271 & 1.52 & 1.00 & & & 1.00 & & \\
\hline Yes & 1224 & 37 & 3.02 & 2.01 & $1.42-2.84$ & $<0.001$ & 3.66 & $2.31-5.81$ & $<0.001$ \\
\hline \multicolumn{10}{|c|}{ Multiple pregnancy } \\
\hline No & 20338 & 336 & 1.65 & 1.00 & & & 1.00 & & \\
\hline Yes & 305 & 33 & 10.82 & 7.20 & $4.95-10.49$ & $<0.001$ & 3.57 & $1.81-7.05$ & $<0.001$ \\
\hline
\end{tabular}


TABLE 3: Continued.

\begin{tabular}{|c|c|c|c|c|c|c|c|c|c|}
\hline & \multirow{2}{*}{ Total } & \multicolumn{2}{|c|}{$\mathrm{AS}^{5 \min }<7$} & \multicolumn{3}{|c|}{ Univariate logistic regression } & \multicolumn{3}{|c|}{ Multivariate logistic regression } \\
\hline & & $n$ & $(\%)$ & OR & $95 \%$ conf. int. & $P$ & OR & $95 \%$ conf. int. & $P$ \\
\hline \multicolumn{10}{|l|}{ Preeclampsia } \\
\hline No & 20092 & 334 & 1.66 & 1.00 & & & & & \\
\hline Yes & 551 & 35 & 6.35 & 4.01 & $2.80-5.74$ & $<0.001$ & - & - & - \\
\hline \multicolumn{10}{|l|}{ Induction } \\
\hline No & 18067 & 299 & 1.65 & 1.00 & & & & & \\
\hline Yes & 2576 & 70 & 2.72 & 1.65 & $1.27-2.15$ & $<0.001$ & - & - & - \\
\hline \multicolumn{10}{|c|}{ CTG at admission } \\
\hline Normal & 16524 & 214 & 1.30 & 1.00 & & & 1.00 & & \\
\hline Nonnormal & 1176 & 36 & 3.06 & 2.47 & $1.73-3.53$ & $<0.001$ & 1.95 & $1.45-2.62$ & $<0.001$ \\
\hline
\end{tabular}

information on height and/or weight was lacking in 2103 individuals $(10.2 \%)$, of which 68 were in the group $\mathrm{AS}^{5 \mathrm{~min}}<$ $7(3.2 \%)$, which is a slight overrepresentation and implies that the results regarding BMI as a risk factor might have to be interpreted with some caution, although this has been verified in previous studies $[10,11]$. It is interesting to note that maternal height is of such importance, as this appears to be an empirical observation made by experienced midwives and obstetricians. This has also previously been shown both nationally [16] and internationally $[8,9]$, although the latter studies are older. The risk factors nulliparity $[10,16]$ and previous cesarean section [16] are also in line with the results of other studies. One must bear in mind, however, that the comparison of risk factors in an international perspective might be difficult, as antenatal care as well as obstetric care is conducted under completely different conditions in large parts of the world compared to the southeastern region of Sweden.

Concerning the frequency of low Apgar scores in relation to different modes of delivery we have looked at the frequency per se, since there was no possibility in this kind of study to evaluate indications, for example, a pathological CTG pattern for operative vaginal delivery or cesarean section. It might be valuable to investigate this, since a Swedish study showed that two-thirds of children born after 33 weeks of gestation with an $\mathrm{AS}^{5 \mathrm{~min}}<7$ were subject to substandard care during labor, where the most common causes were misinterpretation of CTG, incorrect action based on CTG changes, and nonoptimal use of oxytocin augmentation of labor [17].

We chose to compare two obstetric clinics at a secondary and a tertiary level hospital in the same region of Sweden. There is an established collaboration between the two clinics and obstetric high-risk patients are, in some instances, referred from the secondary level hospital to the tertiary level hospital. From this perspective, risk factors such as differences in obstetric care are important to continually analyze and evaluate. In the univariate logistic regression analysis tertiary level of care was a slight risk factor for low Apgar scores. However, when adjusted for other parameters, such as preterm birth, there was no significant difference regarding the risk profile for $\mathrm{AS}^{5 \mathrm{~min}}<7$ between the two levels of hospital care.
The most evident risk factor for $\mathrm{AS}^{5 \mathrm{~min}}<7$ found in this study was preterm birth $(\mathrm{OR}=8(5-12)$ and $\mathrm{OR}=15(8-29)$ for gestational age $28+0-31+6$ weeks and $<28+0$ weeks, resp.).

The overall rate of preterm birth before 37 weeks of gestation in this population was $7.74 \%$, compared to $5.9 \%$ in the general Swedish population [18]. The reason for the slightly higher incidence of preterm birth in the study population was the referral of preterm deliveries to the tertiary care hospital. In an international perspective the incidence of preterm birth in Sweden is low, compared to, for example, the United States, where preterm birth rates are 12\% [18]. The frequency of preterm births before 32 weeks of gestation was low, even at the tertiary level hospital (1.7\%). The total study population included $260(1.26 \%)$ infants born before 32 weeks of gestation, of which $89(34 \%)$ had an $\mathrm{AS}^{5 \mathrm{~min}}<7$. In comparison, the frequency of $\mathrm{AS}^{5 \text { min }}<7$ among term infants (week $37+0-41+6$ ) was only $1.1 \%$. It has also been previously shown that a very low gestational age and a very low birth weight correlate to low Apgar scores [19].

Since preterm birth was found to be such a strong risk factor for $\mathrm{AS}^{5 \mathrm{~min}}<7$, we chose to investigate this issue further with the material at hand. We found multiple pregnancy to be a very strong factor for preterm birth $(\mathrm{OR}=15(9-24))$, which has been previously confirmed [20]. When dealing with in vitro fertilization, for example, it is, therefore, of vital importance to reduce the risk of multiple pregnancy in order to avoid the risk of preterm birth, which accounts for the vast majority of neonatal morbidity and mortality [21]. Preeclampsia was also found to be a significant risk factor $(\mathrm{OR}=5.5(3.4-8.9))$ for birth before 32 weeks of gestation, although this was anticipated since severe preeclampsia is a cause of medically indicated preterm birth. Previous studies have shown various causes of preterm birth [22], and in line with these results we demonstrated smoking as a risk factor for birth before 32 weeks of gestation, implicating the need for continuous work in the field of health informatics. In a Cochrane review by Chamberlain et al. [23] it was demonstrated that psychosocial interventions for the cessation of smoking during pregnancy were successful, and led to a lower frequency of preterm births. We also found 
TABLE 4: Risk factors for preterm birth before 32 weeks of gestation. Analyses performed by univariate and multivariate logistic regression.

\begin{tabular}{|c|c|c|c|c|c|c|c|c|c|}
\hline \multirow{2}{*}{ Parameter } & \multirow{2}{*}{ Total } & \multicolumn{2}{|c|}{32 weeks } & \multicolumn{3}{|c|}{ Univariate logistic regression } & \multicolumn{3}{|c|}{ Multivariate logistic regression } \\
\hline & & $n$ & $(\%)$ & OR & $95 \%$ conf. int. & $P$ & OR & $95 \%$ conf. int. & $P$ \\
\hline \multicolumn{10}{|l|}{ Age (years) } \\
\hline$\leq 26$ & 5386 & 96 & 1.78 & 1.00 & & & 1.00 & & \\
\hline $27-30$ & 5975 & 47 & 0.79 & 0.92 & $0.82-1.03$ & & 0.98 & $0.84-1.16$ & \\
\hline $31-33$ & 4341 & 54 & 1.24 & 0.84 & $0.68-1.05$ & & 0.97 & $0.70-1.34$ & \\
\hline$\geq 34$ & 4915 & 63 & 1.28 & 0.78 & $0.56-1.08$ & 0.135 & 0.95 & $0.59-1.54$ & 0.84 \\
\hline \multicolumn{10}{|c|}{ Height (cms) } \\
\hline$\geq 175$ & 1800 & 18 & 1.00 & 1.00 & & & & & \\
\hline $159-174$ & 14992 & 99 & 0.66 & 1.11 & $0.77-1.59$ & & & & \\
\hline$\leq 158$ & 2084 & 23 & 1.10 & 1.22 & $0.59-2.54$ & 0.588 & - & - & - \\
\hline \multicolumn{10}{|c|}{ BMI $\left(\mathrm{kg} / \mathrm{m}^{2}\right)$} \\
\hline$<25$ & 11359 & 80 & 0.70 & 1.00 & & & & & \\
\hline $25-29.9$ & 4862 & 39 & 0.80 & 1.09 & $0.87-1.38$ & & & & \\
\hline$\geq 30$ & 2319 & 19 & 0.82 & 1.19 & $0.75-1.89$ & 0.448 & - & - & - \\
\hline \multicolumn{10}{|l|}{ Smoking } \\
\hline No & 15784 & 108 & 0.68 & 1.00 & & & 1.00 & & \\
\hline Yes & 3236 & 34 & 1.05 & 1.54 & $1.05-2.27$ & 0.029 & 1.61 & $1.07-2.41$ & 0.022 \\
\hline \multicolumn{10}{|c|}{ Thyroid disease } \\
\hline No & 18379 & 131 & 0.71 & 1.00 & & & 1.00 & & \\
\hline Yes & 550 & 10 & 1.82 & 2.58 & $1.35-4.93$ & 0.004 & 2.32 & $1.17-4.57$ & 0.015 \\
\hline \multicolumn{10}{|c|}{ Type 1 diabetes mellitus } \\
\hline No & 18823 & 134 & 0.71 & 1.00 & & & & & \\
\hline Yes & 140 & 1 & 0.71 & 1.00 & $0.16-6.28$ & 0.997 & - & - & - \\
\hline \multicolumn{10}{|c|}{ Inflammatory bowel disease } \\
\hline No & 18762 & 194 & 1.03 & 1.00 & & & & & \\
\hline Yes & 138 & 3 & 2.17 & 2.12 & $0.67-6.71$ & 0.201 & - & - & - \\
\hline \multicolumn{10}{|l|}{ Epilepsy } \\
\hline No & 18798 & 137 & 0.73 & 1.00 & & & 1.00 & & \\
\hline Yes & 158 & 4 & 2.53 & 3.54 & $1.29-9.67$ & 0.014 & 3.14 & $1.13-8.78$ & 0.029 \\
\hline \multicolumn{10}{|l|}{ Parity } \\
\hline 0 & 8418 & 82 & 0.97 & 1.00 & & & 1.00 & & \\
\hline$\geq 1$ & 10602 & 60 & 0.57 & 0.58 & $0.41-0.81$ & 0.001 & 0.68 & $0.47-0.98$ & 0.036 \\
\hline \multicolumn{10}{|c|}{ Previous cesarean section } \\
\hline No & 17796 & 132 & 0.74 & 1.00 & & & & & \\
\hline Yes & 1224 & 10 & 0.82 & 1.10 & $0.58-2.10$ & 0.768 & - & - & - \\
\hline \multicolumn{10}{|c|}{ Multiple pregnancy } \\
\hline No & 20314 & 216 & 1.06 & 1.00 & & & 1.00 & & \\
\hline Yes & 303 & 44 & 14.52 & 15.8 & $11.2-22.3$ & $<0.001$ & 15 & $10-24$ & $<0.001$ \\
\hline \multicolumn{10}{|c|}{ Preeclampsia } \\
\hline No & 20067 & 214 & 1.07 & 1.00 & & & 1.00 & & \\
\hline Yes & 550 & 46 & 8.36 & 8.47 & $6.09-11.78$ & $<0.001$ & 5.48 & $3.39-8.86$ & $<0.001$ \\
\hline
\end{tabular}

thyroid disease and epilepsy to be independent significant risk factors for birth before 32 weeks of gestation. The number of cases of maternal thyroid disease are relatively few $(n=$ 550 , of which only 10 infants were born before 32 weeks) and the data does not differ between different types of thyroid dysfunction. However, the function of the thyroid gland is central in human reproduction and untreated thyroid disorders are known to increase the risk of several adverse outcomes in pregnancy, of which preterm birth is one [24].
Furthermore, we showed that parturients who were $\geq 1$-para, had a decreased risk for preterm birth implying the need for more thorough monitoring of pregnancies in primigravidae.

Although this project provided valuable baseline data, there is reason to pursue these analyses on a regular basis, to detect trends, for example, in frequency of cesarean sections, inductions, and instrumental vaginal deliveries. Furthermore, the average BMI among pregnant women, as well as the proportion of obese pregnant women, has been 
shown to be increasing $[25,26]$. This is the single risk factor for low Apgar scores shown in this study possible to influence, which stresses the importance of working intensely with this issue to reduce obesity and call attention to associated risks, not only regarding pregnancy outcome but regarding cardiovascular and metabolic diseases. These results may constitute the basis for intervention studies such as those conducted on obese mothers in Linköping, Sweden [27]. Although this study could not demonstrate obesity as a risk factor for preterm birth, meta-analyses show an association between these two conditions [28]. If interventions could lead to a reduced degree of obesity among pregnant women, we might see an effect on the frequency of preterm birth and thereby a lower incidence of low Apgar scores as well.

\section{Conclusion}

Preterm birth is the most evident risk factor for low Apgar scores, and interventions to prevent preterm birth are of importance in improving neonatal outcome. From a clinical perspective efforts are needed to reduce maternal obesity and smoking, since these two risk factors are possible to influence.

\section{Conflict of Interests}

The authors declare that there is no conflict of interests regarding the publication of this paper.

\section{Acknowledgment}

This work was supported by the Medical Research Council of Southeast Sweden.

\section{References}

[1] International Statistical Classification of Diseases and Related Health Problems 10th Revision, http://www.who.int/classifications/icd/en/.

[2] S. Iliodromiti, D. F. Mackay, G. C. S. Smith, J. P. Pell, and S. M. Nelson, "Apgar score and the risk of cause-specific infant mortality: a population-based cohort study," The Lancet, vol. 384, no. 9956, pp. 1749-1755, 2014.

[3] D. Moster, R. T. Lie, L. M. Irgens, T. Bjerkedal, and T. Markestad, "The association of Apgar score with subsequent death and cerebral palsy: a population-based study in term infants," Journal of Pediatrics, vol. 138, no. 6, pp. 798-803, 2001.

[4] M. Wennergren, M. Krantz, O. Hjalmarson, and K. Karlsson, "Low Apgar score as a risk factor for respiratory disturbances in the newborn infant," Journal of Perinatal Medicine, vol. 15, no. 2, pp. 153-160, 1987.

[5] K. Källén, "The impact of maternal smoking during pregnancy on delivery outcome," European Journal of Public Health, vol. 11, no. 3, pp. 329-333, 2001.

[6] D. E. Odd, P. Doyle, D. Gunnell, G. Lewis, A. Whitelaw, and F. Rasmussen, "Risk of low Apgar score and socioeconomic position: a study of Swedish male births," Acta Paediatrica, vol. 97, no. 9, pp. 1275-1280, 2008.

[7] I. Milsom, L. Ladfors, K. Thiringer, A. Niklasson, A. Odeback, and E. Thornberg, "Influence of maternal, obstetric and fetal risk factors on the prevalence of birth asphyxia at term in a Swedish urban population," Acta Obstetricia et Gynecologica Scandinavica, vol. 81, no. 10, pp. 909-917, 2002.

[8] A. P. Camilleri, "The obstetric significance of short stature," European Journal of Obstetrics Gynecology and Reproductive Biology, vol. 12, no. 6, pp. 347-356, 1981.

[9] B. Kappel, G. Eriksen, K. B. Hansen et al., "Short stature in Scandinavian women. An obstetrical risk factor," Acta Obstetricia et Gynecologica Scandinavica, vol. 66, no. 2, pp. 153-158, 1987.

[10] S. Straube, M. Voigt, G. Jorch, E. Hallier, V. Briese, and U. Borchardt, "Investigation of the association of Apgar score with maternal socio-economic and biological factors: an analysis of German perinatal statistics," Archives of Gynecology and Obstetrics, vol. 282, no. 2, pp. 135-141, 2010.

[11] M. Chen, C. McNiff, J. Madan, E. Goodman, J. M. Davis, and O. Dammann, "Maternal obesity and neonatal Apgar scores," The Journal of Maternal-Fetal and Neonatal Medicine, vol. 23, no. 1, pp. 89-95, 2010.

[12] "Obesity: preventing and managing the global epidemic. Report of a WHO consultation," World Health Organization technical report series 894:i-xii, 1-253, 2000.

[13] A. Locatelli, M. Incerti, A. Ghidini, M. Greco, E. Villa, and G. Paterlini, "Factors associated with umbilical artery acidemia in term infants with low Apgar scores at 5 min," European Journal of Obstetrics Gynecology and Reproductive Biology, vol. 139, no. 2, pp. 146-150, 2008.

[14] L. Hogan, I. Ingemarsson, K. Thorngren-Jerneck, and A. Herbst, "How often is a low 5-min Apgar score in term newborns due to asphyxia?" European Journal of Obstetrics Gynecology \& Reproductive Biology, vol. 130, no. 2, pp. 169-175, 2007.

[15] R. Victory, D. Penava, O. da Silva, R. Natale, and B. Richardson, "Umbilical cord $\mathrm{pH}$ and base excess values in relation to adverse outcome events for infants delivering at term," American Journal of Obstetrics and Gynecology, vol. 191, no. 6, pp. 2021-2028, 2004.

[16] S. Berglund, C. Grunewald, H. Pettersson, and S. Cnattingius, "Risk factors for asphyxia associated with substandard care during labor," Acta Obstetricia et Gynecologica Scandinavica, vol. 89, no. 1, pp. 39-48, 2010.

[17] S. Berglund, H. Pettersson, S. Cnattingius, and C. Grunewald, "How often is a low Apgar score the result of substandard care during labour?” BJOG, vol. 117, no. 8, pp. 968-978, 2010.

[18] H. H. Chang, J. Larson, H. Blencowe et al., "Preventing preterm births: analysis of trends and potential reductions with interventions in 39 countries with very high human development index," The Lancet, vol. 381, no. 9862, pp. 223-234, 2013.

[19] M. O. Gardner, R. L. Goldenberg, F. L. Gaudier, M. B. Dubard, K. G. Nelson, and J. C. Hauth, "Predicting low apgar scores of infants weighing less than 1000 grams: the effect of corticosteroids," Obstetrics and Gynecology, vol. 85, no. 2, pp. 170-174, 1995.

[20] R. Romero, J. Espinoza, J. P. Kusanovic et al., "The preterm parturition syndrome," BJOG: An International Journal of Obstetrics and Gynaecology, vol. 113, supplement 3, pp. 17-42, 2006.

[21] L. Myatt, D. A. Eschenbach, S. J. Lye et al., "A standardized template for clinical studies in preterm birth," Reproductive Sciences, vol. 19, no. 5, pp. 474-482, 2012.

[22] R. L. Goldenberg, J. F. Culhane, J. D. Iams, and R. Romero, "Epidemiology and causes of preterm birth," The Lancet, vol. 371, no. 9606, pp. 75-84, 2008. 
[23] C. Chamberlain, A. O'Mara-Eves, S. Oliver et al., "Psychosocial interventions for supporting women to stop smoking in pregnancy," The Cochrane Database of Systematic Reviews, vol. 10, Article ID CD001055, 2013.

[24] R. Negro and J. H. Mestman, "Thyroid disease in pregnancy," Best Practice and Research: Clinical Endocrinology and Metabolism, vol. 25, no. 6, pp. 927-943, 2011.

[25] S. C. Fisher, S. Y. Kim, A. J. Sharma, R. Rochat, and B. Morrow, "Is obesity still increasing among pregnant women? Prepregnancy obesity trends in 20 states, 2003-2009," Preventive Medicine, vol. 56, no. 6, pp. 372-378, 2013.

[26] J. Brynhildsen, A. Sydsjö, E. Norinder, K. Ekholm Selling, and G. Sydsjö, "Trends in body mass index during early pregnancy in Swedish women 1978-2001," Public Health, vol. 120, no. 5, pp. 393-399, 2006.

[27] I.-M. Claesson, G. Sydsjö, J. Brynhildsen et al., "Weight gain restriction for obese pregnant women: a case-control intervention study," British Journal of Obstetrics and Gynaecology, vol. 115, no. 1, pp. 44-50, 2008.

[28] S. D. McDonald, Z. Han, S. Mulla, and J. Beyene, "Overweight and obesity in mothers and risk of preterm birth and low birth weight infants: systematic review and meta-analyses," The British Medical Journal, vol. 341, Article ID c3428, 2010. 


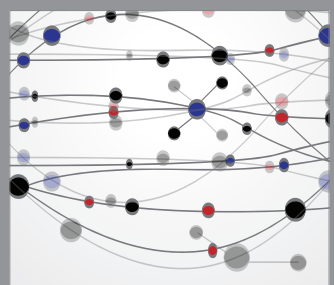

The Scientific World Journal
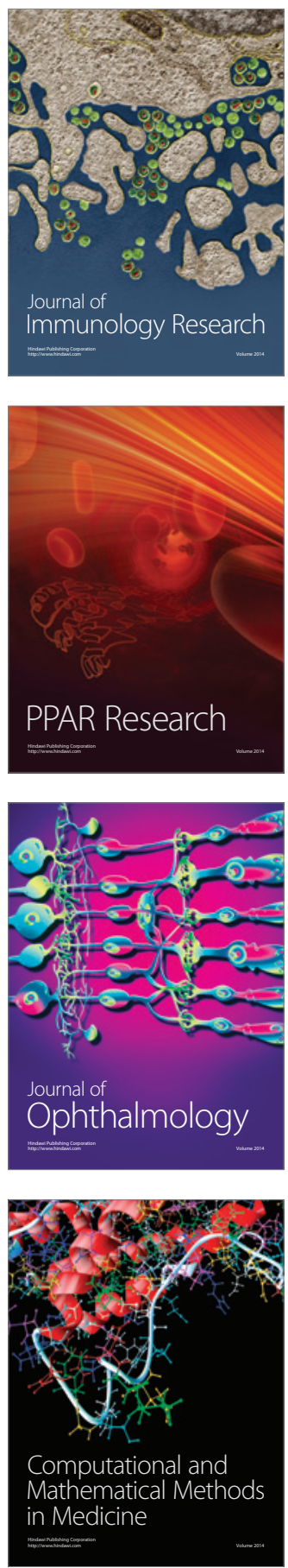

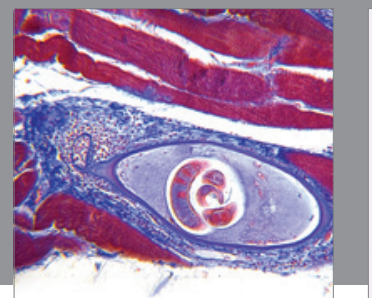

Gastroenterology

Research and Practice
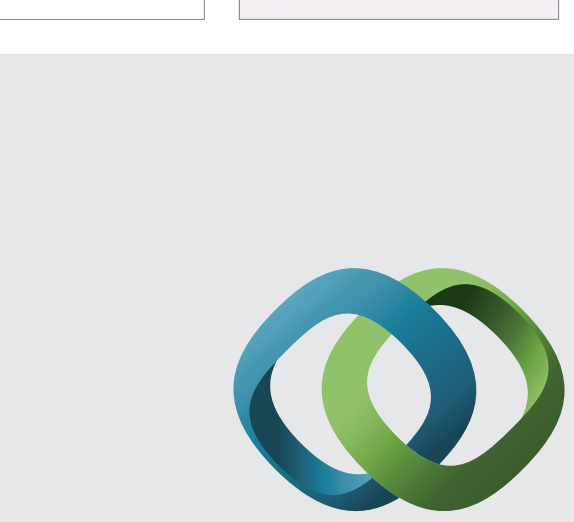

\section{Hindawi}

Submit your manuscripts at

http://www.hindawi.com
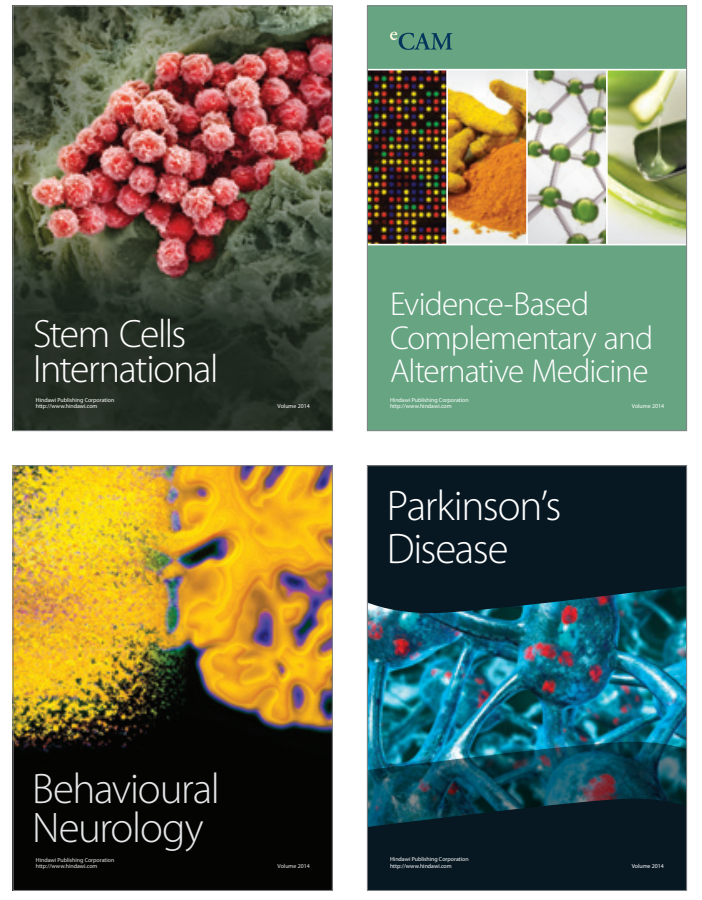
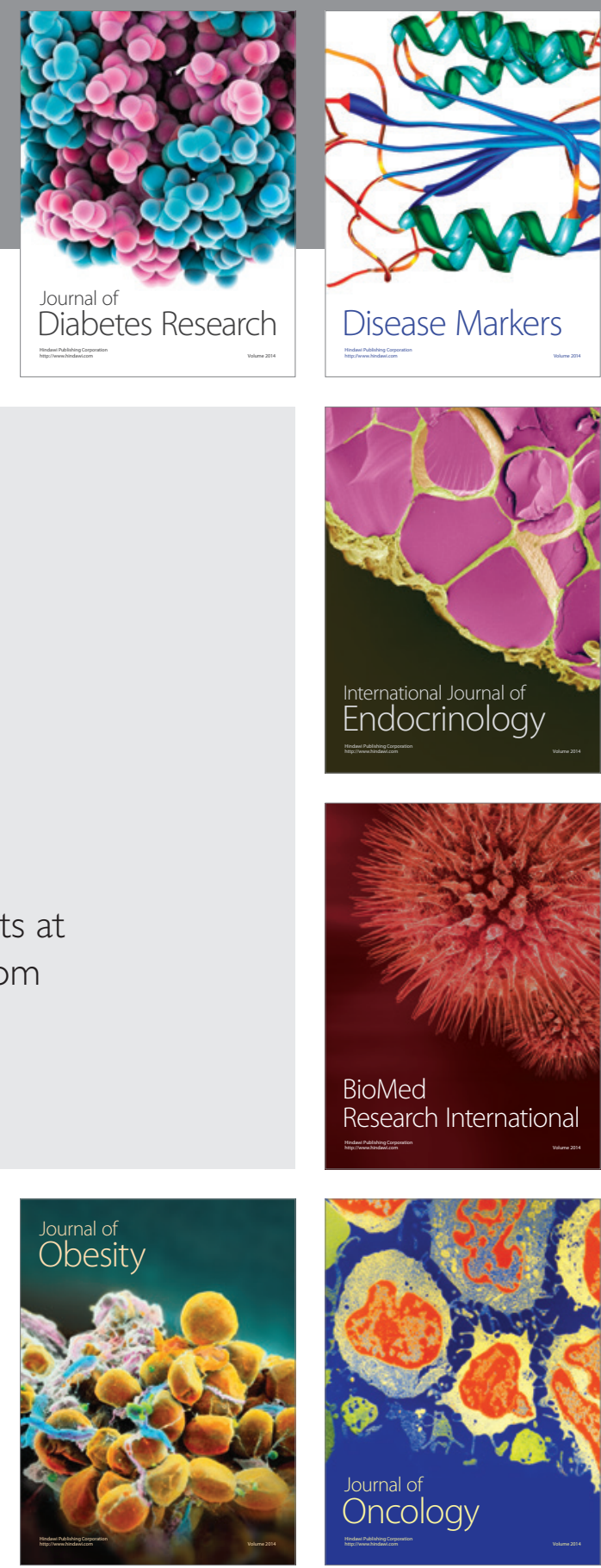

Disease Markers
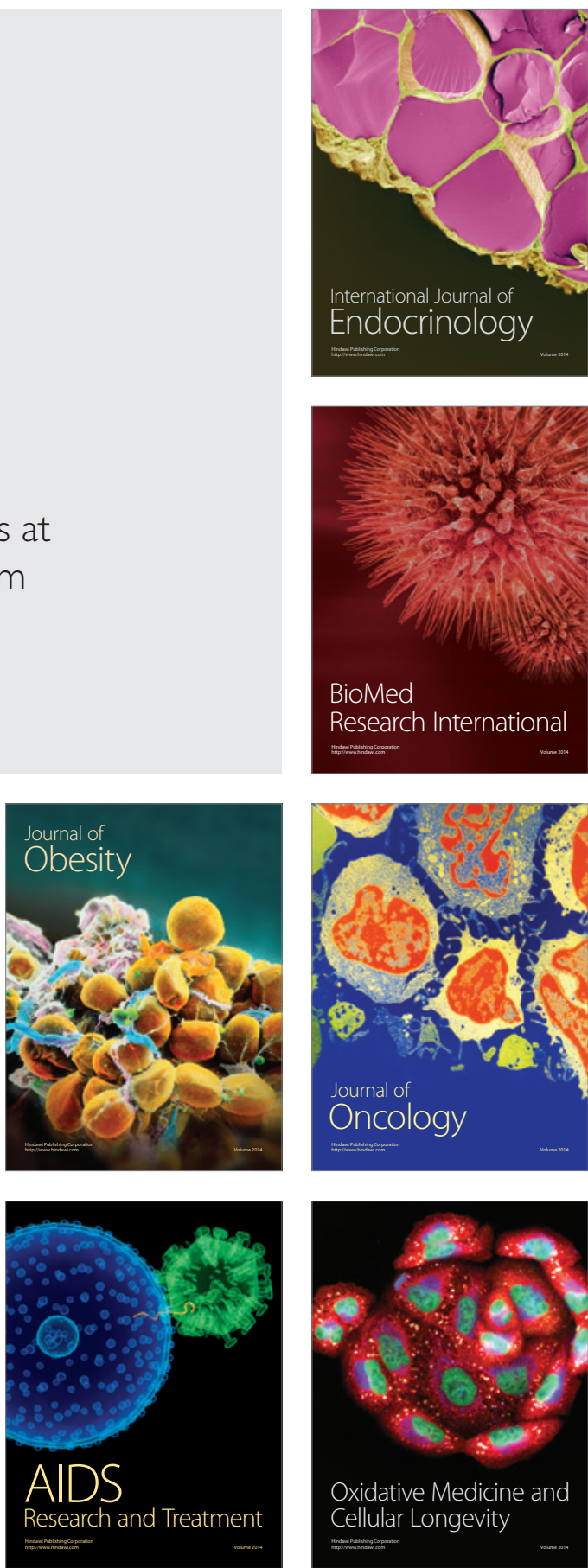